\title{
REVISÃO
}

\section{NUTRIÇÃO MINERAL E QUALIDADE DO FRUTO DO ABACAXIZEIRO E DO MARACUJAZEIRO'}

\author{
JESUS AULAR ${ }^{2}$, MARIA CASARES², WILLIAM NATALE ${ }^{3}$
}

RESUMO-Vários fatores influenciam a produtividade e a qualidade dos frutos do abacaxizeiro e do maracujazeiro, dentre os quais se destacam: o clima, o solo e as práticas de adubação e de irrigação. A nutrição mineral é essencial para elevar a produtividade e melhorar a qualidade dos frutos; no entanto, há poucas informações sobre o efeito da adubação nestas duas frutíferas, especialmente sob condições tropicais. O objetivo desta revisão foi compilar e apresentar os principais resultados de pesquisas, nas quais foi avaliada a influência da nutrição mineral sobre a qualidade destas duas frutíferas. Consideraram-se as informações publicadas recentemente em revistas científicas, sendo as mesmas apresentadas para os macronutrientes de forma individual, em seguida para N-P-K e, por último, para os micronutrientes. A revisão da literatura mostrou que é difícil afirmar que algum elemento favorece ou não determinada característica dos frutos do abacaxizeiro e do maracujazeiro, já que os resultados são variáveis ou existe pouca informação. Em função disso, mais do que deixar estabelecidos os efeitos dos elementos minerais sobre a qualidade dos frutos, o que chama a atenção é a necessidade de pesquisar sobre este tema.

Termos para indexação: Ananas comosus L. Merril, Passiflora edulis f. Flavicarpa Deg., macronutrientes, micronutrientes.

\section{MINERAL NUTRITION AND FRUIT QUALITY OF PINEAPLE AND PASSION FRUIT}

\begin{abstract}
Several factors influence the productivity and fruit quality of pineapple and passion fruit, among which are: climate, soil fertilization and irrigation practices. Mineral nutrition is essential to increase productivity and improve fruit quality; however, there is a few information about the effect of fertilization in these two fruit crops, especially under tropical conditions. The objective of this review was to compile the main research results, in which the influence of mineral nutrition on the fruit quality was evaluated. We considered the information recently published in scientific journals, and presented it for the macronutrients individually, then to NPK and, finally, the micronutrients. The review showed that it is difficult to say that some element favors or not certain characteristics of pineapple and passion fruit fruits, since the results are inconsistent and there is not many information. More than established the effects of mineral nutrients on the fruit quality of these two fruit crops, we stand out that research in this topic is very necessary.
\end{abstract}

Index Terms : Ananas comosus L. Merril, Passiflora edulis f. Flavicarpa Deg., macronutrient, micronutrient.

'(Trabalho 269-14). Recebido em: 20-10-2014. Aceito para publicação: .05-12-2014.

${ }^{2}$ Universidad Centroccidental 'Lisandro Alvarado'- Posgrado de Horticultura- Venezuela. Proyecto UCLA-LOCTI 536-AG-2007. E-mails: jesusaular@ucla.edu.ve; mariacasares@ucla.edu.ve

${ }^{3}$ UNESP-Universidade Estadual Paulista - Campus Jaboticabal. Bolsista PQ-CNpq. E-mail: natale@fcav.unesp.br 


\section{INTRODUÇÃO}

Revisões de literatura englobando o efeito da nutrição mineral sobre a qualidade do fruto têm sido realizadas, predominantemente com frutas de zonas temperadas. Como exemplo, pode-se afirmar para a maçã que: o nitrogênio $(\mathrm{N}), \mathrm{o}$ fósforo $(\mathrm{P}), \mathrm{o}$ potássio $(\mathrm{K})$ e o cálcio $(\mathrm{Ca})$ são os elementos mais estudados, pois estão fortemente relacionados ao rendimento, à qualidade e aos distúrbios fisiológicos. $\mathrm{O}$ teor de minerais, tanto nas folhas como nos frutos, oferece melhor modelo de predição que quando se usa isoladamente o teor de minerais nas folhas. Para a predição de desordens fisiológica, apenas o $\mathrm{Ca}$ e o $\mathrm{N}$ deveriam ser usados. A relação $\mathrm{Ca} / \mathrm{N}$ é uma informação confiável para prever a qualidade. Frutos com altos níveis de $\mathrm{N}$ apresentam maior taxa de respiração e evolução do etileno. A concentração de boro (B) na fruta é um indicador mais sensível que o B foliar, para predizer a probabilidade de amolecimento interno dos frutos (FALLAHI et al., 2010).

Considerando que a informação gerada para frutas temperadas pode, ou não, ser válida para frutas tropicais, deve-se revisar o que tem sido feito com estas últimas nos trópicos. Assim, Aular e Natale (2013) compilaram e apresentaram informações sobre os efeitos dos nutrientes minerais sobre a qualidade dos frutos da goiabeira, da mangueira, da bananeira e do mamoeiro. Os autores informam que, para essas frutíferas, existe variação de resultados sobre os efeitos da aplicação de fertilizantes na qualidade dos frutos. Desse modo, um elemento pode afetar, ou não, determinada característica de qualidade, sendo esse efeito dependente das condições edafoclimáticas, da cultivar, da dose do nutriente, entre outros fatores. Muitos aspectos ligados à qualidade são influenciados de maneira limitada pelos elementos minerais, ao passo que as condições climáticas exercem efeito mais acentuado, o que pode explicar a divergência dos resultados das pesquisas. $\mathrm{O}$ aumento da produção à custa da elevação das doses de fertilizantes pode provocar redução da qualidade dos frutos, afetando o tamanho, a resistência ao transporte e ao armazenamento, a coloração interna e externa, bem como o teor de sólidos solúveis totais (SST).

O objetivo desta revisão foi compilar e apresentar resultados de pesquisas realizadas com o abacaxizeiro (Ananas comosus L. Merril) e o maracujazeiro (Passiflora edulis f. Flavicarpa Deg.), avaliando-se a influência da nutrição mineral sobre a qualidade dos frutos.

Consideraram-se as informações publicadas na ultima década e meia em revistas científicas, sendo as mesmas apresentadas para os macronutrientes de forma individual, em seguida para N-P-K e, por último, para os micronutrientes. A ordem de apresentação das informações seguiu a cronologia de publicação do artigo citado, devendo-se destacar que houve nutrientes para os quais não foi encontrada qualquer informação.

\section{RESULTADOS DE PESQUISA COM A CULTURA DO ABACAXI}

A nutrição mineral tem grande influência sobre o crescimento e, consequentemente, sobre a produção e a qualidade dos frutos. No entanto, há poucas informações sobre o efeito da adubação obtidas no abacaxizeiro, especialmente sob condições tropicais (AMORIM et al., 2013).

Os efeitos do $\mathrm{N}$ sobre a qualidade dos frutos têm sido objeto de pesquisas; porém, é escassa a informação sobre esses efeitos em cultivares recentemente desenvolvidas, como a cv. Vitória, que é resistente à fusariose. Assim, foi avaliada a resposta desse abacaxizeiro em termos de nutrição mineral, produção e qualidade dos frutos, à aplicação de doses crescentes de $\mathrm{N}$, na região de Tabuleiros Costeiros, Estado da Paraíba, Brasil. Foram usadas as seguintes doses: $100 ; 200 ; 300 ; 500$ e $600 \mathrm{~kg} \mathrm{ha}^{-1}$ de N (ureia), aos $60 ; 180$ e 270 dias após o plantio. Com base nos resultados, observou-se que os valores de peso do fruto e de produtividade aumentaram com a elevação das doses de N. Porém, as diferentes doses de $\mathrm{N}$ não alteraram a qualidade dos frutos, a qual se mostrou compatível com as características descritas para a cultivar estudada (SILVA et al., 2012)

$\mathrm{O} \mathrm{K}$ é o nutriente mais importante para a cultura do abacaxi, e a falta deste nutriente reduz o crescimento da planta e a produção, afetando também a qualidade dos frutos (QUAGGIO et al., 2009). Para analisar os efeitos do K sobre o crescimento, o rendimento da planta e a qualidade dos frutos de abacaxizeiros cultivados na Malásia, foram testadas seis doses de potássio: 0; 266; 532; 798; 1.064 e 1.330 $\mathrm{kg} \mathrm{ha}^{-1}$ de $\mathrm{K}_{2} \mathrm{O}$. Os experimentos foram realizados com a cv. Gandul. A aplicação de K não teve qualquer efeito sobre o crescimento das plantas e a qualidade dos frutos, e tampouco afetou os açúcares e a acidez dos frutos. Os autores concluem que aplicações de $\mathrm{K}$ a taxas elevadas tendem a deprimir o crescimento e a produção do abacaxizeiro (RAZZAQUEA; HANAFI, 2001).

$\mathrm{O} \mathrm{K}$ exerce influência acentuada na composição química do abacaxi, com consequente efeito no Índice de Escurecimento Interno do Fruto (EI). Para avaliar a influência de doses crescentes deste elemento sobre o EI, foram estudadas seis doses de K: $0 ; 4 ; 8 ; 12,16$ e 20 g de $\mathrm{K}_{2} \mathrm{O} \cdot$ planta $^{-1} \cdot$ ciclo $^{-1}$, sob a forma de cloreto de potássio. Após a colheita, os frutos foram submetidos ao armazenamento refrigerado, à temperatura de $7{ }^{\circ} \mathrm{C}$. Com base nos resultados, verificou-se que o EI dos frutos diminuiu com as doses de 16 e $20 \mathrm{~g}$ de $\mathrm{K}_{2} \mathrm{O} \cdot$ planta $^{-1} \cdot$ ciclo $^{-1}$ (BOTREL et al., 2004).

Para avaliar o efeito da aplicação de K no solo 
sobre o desenvolvimento do EI, foram aplicadas entre 4 e $20 \mathrm{~g}$ de $\mathrm{K}_{2} \mathrm{O}$ por planta, em três parcelamentos, aos $8 ; 24$ e 40 semanas após o plantio (AP). Os frutos foram colhidos 19 meses AP, em dois pontos de maturação, classificados como quebra de cor (QC) e meio maduro (MM), e o abacaxi foi armazenado a $7{ }^{\circ} \mathrm{C}$ e $95 \%$ de umidade relativa, por 15 dias, seguido de 5 dias a $25{ }^{\circ} \mathrm{C}$, para simular o manuseio comercial. A aplicação de potássio reduziu o EI dos frutos de ambas as maturidades. Houve redução do conteúdo fenólico das frutas das plantas tratadas com $\mathrm{K}$. A atividade das enzimas polifenoloxidase (PPO) e fenilalanina amonia-liase (PAL) variou segundo o ponto de maturidade, com maior atividade no fruto MM. O tratamento com K promoveu diminuição progressiva da atividade da PPO em frutos MM, quando comparados aos frutos QC. Da mesma forma, as atividades de PAL e PPO foram menores nos frutos de plantas tratadas com $\mathrm{K}$, assim como a incidência de IB. O trabalho mostrou que as aplicações de $\mathrm{K}$ no solo, para o cultivo do abacaxizeiro, podem melhorar a qualidade do fruto (SOARES et al., 2005).

Para determinar a resposta do abacaxizeiro 'Smooth Cayenne' às fontes e doses de potássio, foram consideradas quatro doses $(0 ; 175 ; 350$ e 700 $\left.\mathrm{kg} \mathrm{K}_{2} \mathrm{O} \cdot \mathrm{ha}^{-1}\right)$ e três combinações de fontes de $\mathrm{K}$ (100 $\% \mathrm{KCl} ; 100 \% \mathrm{~K}_{2} \mathrm{SO}_{4}$ e $\left.40 \% \mathrm{~K}_{2} \mathrm{SO}_{4}+60 \% \mathrm{KCl}\right)$. A acidez titulável total (ATT) aumentou em resposta à aplicação de $\mathrm{K}$, especialmente com o emprego do $\mathrm{KCl}$. O uso de $\mathrm{K}_{2} \mathrm{SO}_{4}$ resultou em menor relação SST/ATT, especialmente nas doses mais elevadas de K. A firmeza dos frutos diminuiu com o aumento do período de armazenamento, sendo este efeito maior sem aplicação K. A qualidade dos frutos de abacaxizeiro foi mais afetada pelas doses de $\mathrm{K}$ do que pelas fontes utilizadas (QUAGGIO et al., 2009).

Alguns experimentos foram conduzidos para estudar os efeitos da adubação N-P-K sobre a qualidade do fruto do abacaxizeiro. Teixeira et al. (2002) analisaram o efeito do parcelamento da adubação N-P-K no abacaxizeiro 'Smooth Cayenne' produzido em Agudos-SP, Brasil. Observou-se que os frutos, colhidos 21 meses após o plantio, tiveram sua massa média e na qualidade influenciadas pela forma de parcelamento da adubação com $\mathrm{N}$ e K enquanto o fracionamento da adubação fosfatada não afetou a produção. O parcelamento com aplicação mais tardia de $\mathrm{N}$ aumentou a produção; contudo, teve efeito negativo sobre o teor de SST dos frutos. Na mesma localidade e com a mesma cultivar, foi desenvolvido um experimento para examinar os efeitos de doses de N-P-K sobre a produção e a qualidade de frutos do abacaxizeiro. O P foi aplicado somente no plantio, nas doses de $0 ; 80 ; 160$ e $320 \mathrm{~kg} \cdot \mathrm{ha}^{-1} \mathrm{de}_{2} \mathrm{O}_{5}$, como superfosfato simples. As doses de $\mathrm{N}$ e $\mathrm{K}_{2}^{2} \mathrm{O}$ foram 0; 175; 350 e 700 kg.ha- ${ }^{-1}$, aplicadas como ureia e cloreto de potássio, respectivamente, parceladas em quatro aplicações, durante o período de crescimento da cultura. Não foi observado efeito das doses de P no crescimento, na produção e na qualidade, mesmo com a baixa disponibilidade do nutriente no solo da área experimental. $\mathrm{O}$ aumento nas doses de $\mathrm{N}$ diminuiu o teor de SST e ATT, enquanto o oposto ocorreu com as doses de K, que elevaram, ainda, os teores de vitamina C (SPIRONELLO et al., 2004).

Foi avaliada a resposta da cultivar 'Josapine' quanto à densidade de plantio e às doses de fertilizantes, na localidade de Kelantan, Malasia. Foram usadas quatro densidades de plantio (10.759; $12.911 ; 21.578$ e 25822 plantas.ha $^{-1}$ ) e duas doses de fertilizante de 40 e 60 g. planta $^{-1}\left(\mathrm{~N}_{-} \mathrm{P}_{2} \mathrm{O}_{5}-\mathrm{K}_{2} \mathrm{O}-\mathrm{MgO}\right.$ $=12-12-17-2)$. O rendimento estimado do fruto foi significativamente maior com densidades mais elevadas, embora os tamanhos dos frutos fossem significativamente menores. O comprimento da coroa, o peso da coroa, o teor de açúcares e o ácido dos frutos não foram afetados pelas densidades ou doses de fertilizantes. No entanto, o comprimento e o diâmetro do fruto foram significativamente menores para as densidades mais elevadas e para a maior dose de fertilizante (SELAMAT ;MASAUD, 2005).

Na localidade de Sooretama-ES, Brasil, foi avaliado o efeito da adubação com N, P e K na qualidade dos frutos do abacaxizeiro Gold (MD-2). Os tratamentos foram formados por cinco doses de N, cinco de $\mathrm{P}_{2} \mathrm{O}_{5}$ e cinco de $\mathrm{K}_{2} \mathrm{O}$, combinadas segundo a matriz experimental $(2 \mathrm{k}+2 \mathrm{k}+1)$, sendo os limites mínimos e máximos de 0 a $1.000 ; 0$ a 400 e 0 a $1.000 \mathrm{~kg} \cdot \mathrm{ha}^{-1}$ para $\mathrm{N}, \mathrm{P}_{2} \mathrm{O}_{5}$ e $\mathrm{K}_{2} \mathrm{O}$, respectivamente. Observou-se que o $\mathrm{N}$ em doses crescentes causou efeito linear negativo sobre a ATT, e que o incremento tanto de $\mathrm{P}$ como de $\mathrm{K}$ proporcionou efeito linear positivo sobre os teores de SST e quadrático sobre a ATT, bem como sobre a relação SST/AAT (GUARÇONI; VENTURA, 2011). Foi estudado o efeito de doses de $\mathrm{N}, \mathrm{P}_{2} \mathrm{O}_{5}$ e $\mathrm{K}_{2} \mathrm{O}$ sobre a massa dos frutos, a produtividade e a qualidade da polpa dos frutos do abacaxizeiro 'Vitória'. Os tratamentos foram constituídos de cinco doses de $\mathrm{N}(0 ; 214 ; 428$; 642 e 856 kg.ha $\left.{ }^{-1}\right)$; cinco doses de $\mathrm{P}_{2} \mathrm{O}_{5}(0 ; 75 ; 150$; 225 e 300 kg.ha-1 $)$; e, cinco doses de $\mathrm{K}_{2} \mathrm{O}(0 ; 150$; $300 ; 450$ e $\left.600 \mathrm{~kg} \cdot \mathrm{ha}^{-1}\right)$. O incremento nas doses de $\mathrm{N}$ promoveu maior produtividade e desenvolvimento dos frutos. Os valores de SST e ATT cresceram linearmente em função do aumento das doses de K, ao passo que a elevação das doses de $\mathrm{N}$ apresentou efeito oposto. Mesmo com a baixa disponibilidade de P, não houve resposta a este nutriente (CAETANO et al., 2013).

É conhecida a grande importância da adubação com micronutrientes na qualidade dos frutos; porém, pouco se sabe sobre os efeitos dos micronutrientes nas características do abacaxi, (AMORIM et al., 2013). Para avaliar os efeitos do Boro (B) e do Zinco (Zn), na forma de quelato, ácido ou sal, aplicados via foliar, sobre a produtividade e a qualidade dos frutos da cv. Smooth Cayenne, produzidos em Guaraçaí-SP, Brasil, foram aplicadas, 110 g.ha-1 de B e 250 g.ha-1 
de $\mathrm{Zn}$, em duas pulverizações foliares, aos 7 e 9 meses após o plantio. Os resultados indicaram que as fontes de B e Zn não exerceram qualquer efeito sobre os teores de SST, ATT, diâmetro médio do fruto, comprimento do fruto sem coroa e relação SST/ATT (MAEDA et al., 2011).

Amorim et al. (2013) analisaram o efeito da adubação com os micronutrientes $\mathrm{B}, \mathrm{Cu}$ (Cobre), $\mathrm{Zn}$, Mn (Manganês) e Fe (Ferro), aplicados no solo e via foliar, sobre a qualidade e a aceitação do abacaxi cv. Vitória. Os micronutrientes aumentaram o teor de SST e a relação SST/ATT, especialmente quando aplicados via foliar, promovendo maior peso e comprimento dos frutos. Portanto, esses efeitos positivos dos micronutrientes podem ter contribuído para a boa aceitação dos frutos do cv. Vitória no mercado, o que foi evidenciado pela análise sensorial.

$\mathrm{Na}$ Tabela 1, estão apresentados de forma resumida, os efeitos dos elementos minerais sobre as características do fruto do abacaxizeiro. Os principais efeitos positivos sobre a qualidade correspondem ao $\mathrm{K}$ (tamanho de fruto, SST, ATT e SST/ATT), e os negativos, para o N (massa do fruto, SST e ATT). Não obstante, pode-se observar que existe variação na resposta aos nutrientes, em função das características de qualidade desta frutífera, segundo os diferentes autores citados. Assim, o N pode melhorar ou não a massa do fruto, o SST e a ATT; e o K pode afetar, ou não, o tamanho do fruto, o SST, a ATT e a SST/ATT. Resultado similar já tinha sido descrito por Aular e Natale (2013) para manga, banana, goiaba e mamão.

\section{RESULTADOS DE PESQUISA COM A CULTURA DO MARACUJÁ}

Vários fatores influenciam a produtividade do maracujazeiro, dentre os quais podem ser destacados: o clima, o solo e as práticas de adubação e de irrigação. $\mathrm{O}$ atendimento das exigências nutricionais é essencial para elevar a produtividade e melhorar a qualidade dos frutos, sendo o $\mathrm{N}$ o nutriente mais absorvido por esta frutífera (BORGES et al., 2006). $\mathrm{O}$ efeito deste elemento sobre a qualidade do fruto do maracujazeiro tem sido estudado, e os resultados mostraram respostas variáveis. Conduziu-se um experimento em Campos dos Goytacazes-RJ, Brasil, para avaliar o efeito da adubação nitrogenada, com diferentes lâminas de irrigação, sobre a produtividade e a qualidade dos frutos do maracujazeiro-amarelo. Testaram-se quatro doses de N $(50 ; 250 ; 450$ e $650 \mathrm{~g}$. planta $^{-1}$. ano-1 de N), utilizando-se ureia como fonte de nitrogênio, sob seis lâminas de irrigação por gotejamento $(0 ; 25 ; 50 ; 75,100$ e $125 \%$ da ET0 evapotranspiração de referência). Houve resposta na produtividade quando o $\mathrm{N}$ foi aplicado sob a lâmina de irrigação de $50 \%$ da ET0, atingindo-se produtividade máxima de 36 t.ha $^{-1}$ com 273 g.planta ${ }^{-1}$. $\mathrm{ano}^{-1}$. A adubação nitrogenada influenciou o número de frutos e não apresentou influência sobre o peso médio, rendimento de suco, $\mathrm{pH}$, SST, ATT e SST/ATT dos frutos. A irrigação influenciou a produtividade, o peso médio, o comprimento e o diâmetro dos frutos (CARVALHO, 2000).

Para avaliar doses e fontes de N, aplicadas via fertirrigação, sobre a produção e a qualidade dos frutos do maracujá-amarelo, Tabuleiro Costeiro, Estado da Bahia, Brasil, estudaram-se duas fontes de nitrogênio (ureia e nitrato de cálcio) e cinco doses de N $\left(0 ; 100 ; 200 ; 400\right.$ e 800 kg.ha-1 $\left.{ }^{-1}\right)$. Os resultados mostraram que a produtividade máxima de frutos $\left(34,3 \mathrm{tha}^{-1}\right)$ foi atingida com a aplicação de $457 \mathrm{~kg}$ de $\mathrm{N} \mathrm{ha}^{-1}$, na forma de ureia. Não obstante, a adubação nitrogenada e as fontes utilizadas não influenciaram as características do fruto e a qualidade do suco (BORGES et al., 2006).

Freitas et al. (2006) realizaram um experimento em casa de vegetação, com o objetivo de avaliar a qualidade dos frutos do maracujazeiro cultivado sob carência de macronutrientes. Todas as deficiências reduziram o número de frutos por planta e, sob deficiência de $\mathrm{Mg}$, as plantas não floresceram. As carências nutricionais não influenciaram o peso médio dos frutos, o número de sementes por fruto, o comprimento do fruto e a porcentagem de suco. As deficiências de $\mathrm{N}$ e $\mathrm{P}$ aumentaram a espessura e a porcentagem de casca do fruto. As deficiências de N, P e K reduziram o SST; a de K reduziu a ATT; e a de $\mathrm{P}$ diminuiu o $\mathrm{pH}$ e aumentou a concentração da vitamina $\mathrm{C}$, a qual foi reduzida pelas deficiências de $\mathrm{N}, \mathrm{K}$ e S. A deficiência de Ca não afetou a qualidade dos frutos.

A literatura tem relatado que o $\mathrm{K}$ é um dos maiores responsáveis pela qualidade dos frutos. Sendo assim, Fortaleza et al. (2005) avaliaram os efeitos da adubação potássica sobre as características físicas e químicas dos frutos de nove genótipos de maracujazeiro-azedo. Utilizaram-se três doses de potássio: 0; $640 ; 1.280 \mathrm{~kg}$ de $\mathrm{K}_{2} \mathrm{O}$ ha $^{1}$. ano $\left.{ }^{-1}\right)$. Verificou-se efeito quadrático do $\mathrm{K}$ sobre o comprimento do fruto, a espessura da casca e o número médio de sementes por fruto; e efeito linear positivo para o rendimento total e negativo para a relação SST/ATT.

$\mathrm{O}$ efeito da nutrição potássica sobre a qualidade do maracujazeiro-amarelo foi avaliado na Universidade Federal de Viçosa-MG, Brasil. Os tratamentos consistiram em cinco concentrações de $\mathrm{K}\left(1 ; 2 ; 4 ; 6\right.$ e 8 mmol.L -1 $^{-1}$, em solução nutritiva modificada de Hoagland e Arnon. Observou-se que o $\mathrm{K}$ aumentou o rendimento e o peso médio dos frutos até a concentração de 6,43 e 6,24 mmol. $\mathrm{L}^{-1}$, respectivamente; houve incremento linear do número 
de sementes por frutos, do conteúdo de água e da espessura relativa do pericarpo, bem como do teor de vitamina C. Houve resposta quadrática da ATT em função do aumento das doses de $\mathrm{K}$, com ponto de máxima em 5,27 mmol.L ${ }^{-1}$. A porcentagem de polpa, o pH e o teor de SST não foram influenciados pelas doses de K (ARAÚJO et al., 2006).

O maracujazeiro geralmente tem alto teor de ácido cítrico. Porém, frutos menos azedos são cada vez mais procurados para o consumo in natura. Em função disso, foi examinado o efeito do $\mathrm{K}$ na qualidade dos frutos do maracujá, especialmente com relação à acidez. No experimento, foram aplicadas soluções nutritivas contendo $0 ; 6,3 ; 12,5$ e $25,0 \mathrm{mg}$ de K. Verificou-se que a ATT foi menor com a menor taxa de aplicação K. Na dose zero de K, houve baixos teores de SST, apesar de não existir relação estatística entre SST e teor de K no suco. A taxa de aplicação de K não teve efeito sobre a percentagem de suco, o peso e as dimensões dos frutos (KONDO; HIGUCHI, 2013).

Brito et al. (2005) avaliaram a combinação de fontes de adubos orgânicos e doses de potássio sobre o rendimento e a qualidade dos frutos do maracujazeiro, em Sergipe, Brasil. O experimento foi realizado com duas fontes de adubos orgânicos (esterco de frango na dose de $10 \mathrm{~L}$, e esterco de ovino na dose de $20 \mathrm{~L})$, combinadas a cinco doses de $\mathrm{K}(0$; 27; 54; 81 e 108 g planta $^{-1}$ ), e um tratamento adicional $(2,5 \mathrm{~L}$ de esterco de frango e 7,5 $\mathrm{L}$ de esterco de ovino). Os frutos apresentaram atributos adequados para o consumo in natura e para a indústria, quando adubados com esterco de frango ou esterco de ovino, associados às diferentes doses de $\mathrm{K}$, obtendo SST entre 10,8 e 14,02 \%; ATT de 8,48 a 7,57 g. $100 \mathrm{~mL}^{-1}$ de suco; espessura da casca entre 6,52 e 7,12 mm. Os autores não avaliaram os efeitos principias dos adubos orgânicos e do K sobre as características de qualidade dos frutos, o que não permite fazer comentários a esse respeito.

Aplicações de micronutrientes como B e Zn têm-se tornado prática rotineira na cultura do maracujá, provavelmente devido aos ganhos na qualidade, confirmados em outras fruteiras tropicais, mais que em função de resultados obtidos na própria cultura. Porém, quando foi analisado o efeito da deficiência de B sobre a qualidade dos frutos desta planta, verificou-se que a carência não afetou aspectos ligados à qualidade, não influenciando o peso médio, 0 comprimento e a porcentagem de suco dos frutos (FREITAS et al., 2006).

A produção integrada de frutas tem-se tornado uma excelente alternativa para os fruticultores. Em função disso, há necessidade de informações para dar melhor suporte a esta opção de produção. Biofertilizantes de esterco líquido, obtidos a partir de processos anaeróbios, têm surgido como um importante componente do sistema de fornecimento integrado de nutrientes. Assim, foi avaliado o efeito de dois tipos de biofertilizante (uma fonte simples e outra enriquecida com macro e micronutrientes) e cinco doses de cada biofertilizante $(0,0 ; 0,6 ; 1,2$; 1,8 e $\left.2,4 \mathrm{~L} \mathrm{planta}^{-1}\right)$ sobre a qualidade dos frutos e os teores foliares de macronutrientes de plantas de maracujazeiro-amarelo. A qualidade dos frutos e o estado nutricional dessa frutífera foram afetados pelas doses de biofertilizante aplicadas. Os autores não discriminaram os efeitos individuais dos micronutrientes sobre as características dos frutos. $\mathrm{O}$ comprimento do fruto, a largura, a porcentagem de suco, a espessura e a massa da casca, o SST e a ATT foram melhorados com a aplicação de biofertilizantes. O biofertilizante simples proporciona ótima fonte de potássio, cálcio e enxofre, enquanto o enriquecido com fertilizante organomineral promoveu ainda boas fontes de enxofre, $\mathrm{P}, \mathrm{K}$ e cálcio (CAVALCANTE et al., 2012).

Na Tabela 2, pode-se observar um resumo de como alguns nutrientes afetam a qualidade do fruto do maracujazeiro. $\mathrm{N}$, $\mathrm{P}$ e K representaram a maioria dos efeitos positivos sobre a qualidade. Foi observada abundantemente falta de resposta (sem efeito), o que pode significar que devem ser realizados novos estudos buscando confirmar a influência dos nutrientes sobre a qualidade do maracujá, como já foi feito em outras frutíferas.

De forma similar ao indicado para o abacaxizeiro, tampouco existe resposta homogênea para a influência dos nutrientes sobre as variáveis de qualidade. Desse modo, o N afetou, ou não, a massa do fruto e os SSTs, segundo os diferentes autores revisados. Para o K, houve variação na resposta em relação à massa do fruto, à porcentagem de suco e os SST. Para os outros nutrientes, o número de referências foi insuficiente para se fazer inferências sobre seus efeitos na qualidade dos frutos. 


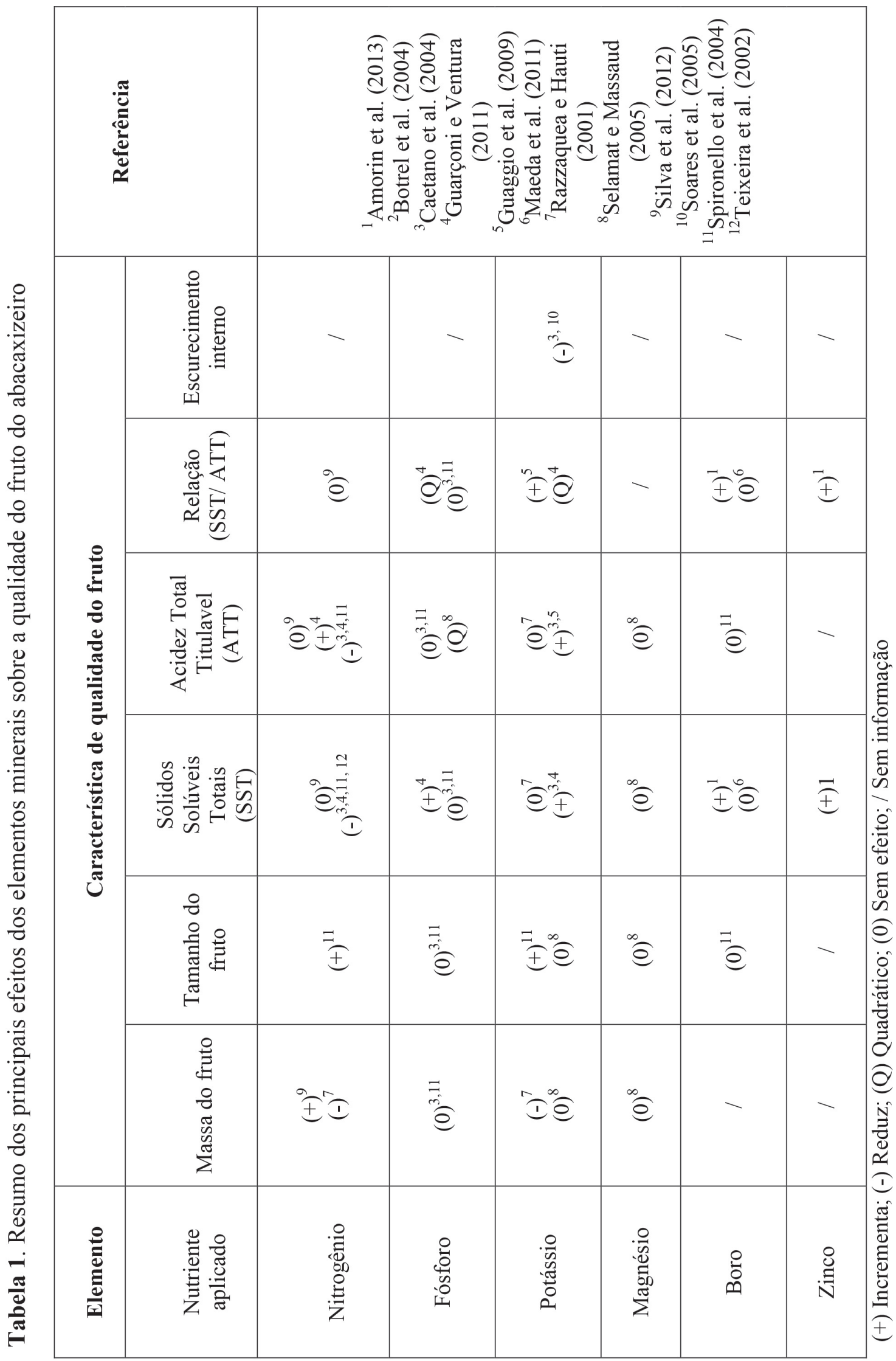




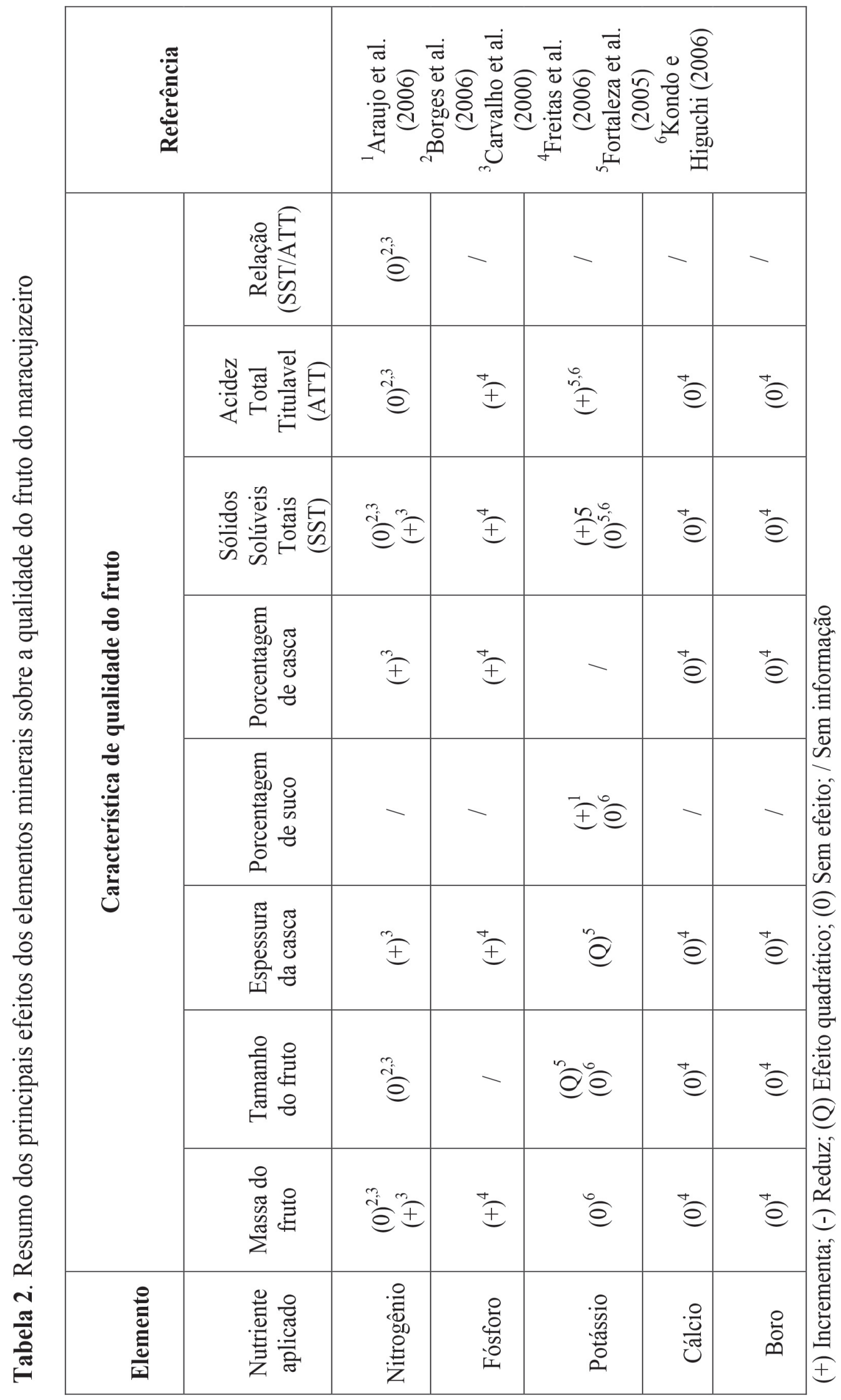




\section{CONCLUSÃO}

As respostas não consistentes e a falta de informações sobre os efeitos dos elementos minerais na qualidade dos frutos mostram que é difícil afirmar, com certeza, que algum elemento favorece, ou não, determinada característica de qualidade do abacaxizeiro e do maracujazeiro.

Nesta revisão, mais do que deixar estabelecidos os efeitos dos elementos minerais sobre a qualidade dos frutos destas duas frutíferas, o que fica evidenciado é que existe necessidade de pesquisar sobre o tema.

\section{REFERÊNCIAS}

AMORIM, A.; GARRUTI, D.; LACERDA, C.; MOURA, C.; GOMES-FILHO, E. Postharvest and sensory quality of pineapples grown under micronutrients doses and two types of mulching. African Journal of Agricultural Research, Lagos, v. 8, n.19, p.2240-2248, 2013.

ARAÚJO, R.; BRUCKNER, C.; MARTINEZ, H.; SALOMÃO, L.; ALVAREZ, V.; SOUZA, A.; PEREIRA, W.; HIZUMI, S. Quality of yellow passion fruit (Passiflora edulis Sims F. flavicarpaDeg.) as affected by potassium nutrition. Fruits, Paris, v.61, p.109-115, 2006.

AULAR, J.; NATALE,W. Nutrição mineral e qualidade do fruto de algumas frutíferas tropicais: goiabeira, mangueira, bananeira e mamoeiro. Revista Brasileira de Fruticultura, Jaboticabal, v.35, n.4, p.1214-1231, 2013.

BORGES, A.; CALDAS, R.; LIMA, A. Doses e fontes de nitrogênio em fertirrigação no cultivo do maracujá-amarelo. Revista Brasileira de Fruticultura, Jaboticabal, v.28, n.2, p.301-304, 2006.

BOTREL, N.; SOUZA, L.; SOARES, A.; MEDINA, V.; FREITAS, S. 2004. Influência do potássio na suscetibilidade ao escurecimento interno do abacaxi 'Pérola' (AnanascomosusL.). Revista Ibereroamericana de Tecnología Postcosecha, Hermosillo, v.6, n.1, p.17-23, 2004.
BRITO, M.; MELO, A.; LUSTOSA, J.; ROCHA, M.; VIÉGAS, P.; HOLANDA, F. Rendimento e qualidade da fruta do maracujazeiro-amarelo adubado com potássio, esterco de frango e de ovino. Revista Brasileira de Fruticultura, Jaboticabal,v.27, n.2, p.260-263, 2005.

CAETANO, L.; VENTURA, J.; COSTA, A.; GUARÇONI, R. Efeito da adubação com nitrogênio, fósforo e potássio no desenvolvimento, na produção e na qualidade de frutos do abacaxi 'Vitória'. Revista Brasileira de Fruticultura, Jaboticabal, v. 35, n.3, p.883-890, 2013.

CARVALHO, A.; MARTINS, D.; MONNERAT, P.; BERNARDO, S. Adubação nitrogenada e irrigação no maracujazeiro-amarelo. I. Produtividade e qualidade dos frutos. Pesquisa Agropecuária Brasileira, Brasília, v.35, n.6, p.1101-1108, 2000.

CAVALCANTE, I.; CAVALCANTE, L.; SANTOS, G.; BECKMANN-CAVALCANTE, M.; SILVA, $\mathrm{S}$. Impact of biofertilizers on mineral status and fruit quality of yellow passion fruit in brazil. Communications in Soil Science and Plant Analysis, New York, v.43, p.2027-2042, 2012.

FALLAHI, E.; FALLAHI, B.; NEILSEN, G.; NEILSEN, D.; PERYEA, F.Effects of mineral nutrition on fruit quality and nutritional disorders in apples. Acta Horticulturae, The Hague, v.868, p. 49-59, 2010.

FORTALEZA, J.; PEIXOTO, J.; JUNQUEIRA, N.; OLIVEIRA, A.; RANGEL, L. Características físicas e químicas em nove genótipos de maracujá- azedo cultivado sob três níveis de adubação potássica. Revista Brasileira de Fruticultura, Jaboticabal, v. 27, n. 1, p. 124-127, 2005.

FREITAS, M.; MONNERAT, P.; PINHO, L.; CARVALHO, A. Deficiência de macronutrientes e boro em maracujazeiro-doce: Qualidade dos frutos.

Revista Brasileira de Fruticultura, Jaboticabal, v.28, n.3, p.492-496, 2006.

GUARÇONI, A.; VENTURA, J. Adubação N-P-K e o desenvolvimento, produtividade e qualidade dos frutos do abacaxi 'Gold' (MD-2). Revista Brasileira de Ciência do Solo, Viçosa, MG, v.35, p.1367-1376, 2011. 
KONDO, T.; HIGUCHI, H. Acidity of passion fruit as affected by potassium fertilizer. Acta Horticulturae, The Hague, v.984, p.385-391. 2013.

MAEDA, A.; BUZETTI, S.; BOLIANI, A.; BENETT, C.; TEIXEIRA FILHO, M.; ANDREOTTI, M. Foliar fertilization on pineapple quality and yield. Pesquisa Agropecuária Tropical, Goiânia, v.41, n.2, p.248253, 2011.

QUAGGIO, J.; TEIXEIRA, L.; CANTARELLA, H.; MELLIS, E.; SIGRIST, J. Post-harvest behaviour of pineapple affected by sources and rates of potassium. Acta Horticulturae, The Hague, v.82, p.277-284, 2009.

RAZZAQUEA, A.; HANAFI, M. Effect of potassium on growth, yield and quality of pineapple in tropical peat. Fruits, Paris, v.56, n.1, p.45-49, 2001.

SELAMAT,M.; MASAUD, R. Growth, yield and quality of pineapple cv.Josapine as affected by density and fertilizer rate grown on sandy soil in Malaysia. Acta Horticulturae, The Hague, v. 666, p.193-201, 2005.
SILVA, A.; SILVA, A.; SOUZA, A.; SANTOS, D.; SILVA, S., SILVA, V. Resposta do abacaxizeiro 'Vitória' a doses de nitrogênio em solos de tabuleiros costeiros da Paraíba. Revista Brasileira de Ciência do Solo, Viçosa, MG, v. 36, n.2, p.447-456, 2012.

SOARES, A.; TRUGO, L.; BOTRELA, N.; SOUZA, L. Reduction of internal browning of pineapple fruit (AnanasComusus L.) by preharvest soil application of potassium. Postharvest Biology and Technology, Amsterdam, v.35, p. 201-207, 2005.

SPIRONELLO, A.; QUAGGIO, J.: TEIXEIRA, L.; PEDRO ROBERTO FURLANI, P.; SIGRIST, J. Pineapple yield and fruit quality affected by NPK fertilization in a tropical soil. Revista Brasileira de Fruticultura, Jaboticabal, v.26, n.1, p.155-159, 2004.

TEIXEIRA, L.; SPIRONELLO, A.; FURLANI, P.;SIGRIST, J. Parcelamento da adubação NPK em abacaxizeiro. Revista Brasileira de Fruticultura, Jaboticabal, v.24, n.1, p.219-224, 2002. 